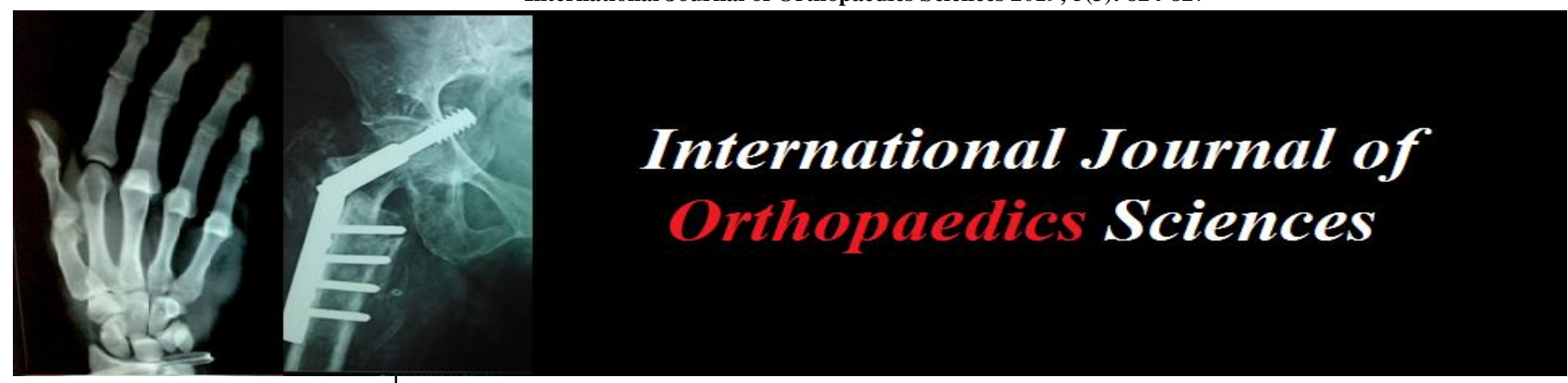

E-ISSN: 2395-1958

P-ISSN: 2706-6630

IJOS 2019; 5(3): 824-827

(C) 2019 IJOS

www.orthopaper.com

Received: 21-05-2019

Accepted: 25-06-2019

Ghanshyam Kakadiya

Senior Resident, Department of

Orthopaedics, TNMC \& BYL

Nair Hospital, Mumbai,

Maharashtra, India

Yogesh Soni

Senior Resident, Department of Orthopaedics, TNMC \& BYL

Nair Hospital, Mumbai,

Maharashtra, India

Viraj Gandbhir

Senior Resident, Department of Orthopaedics, TNMC \& BYL

Nair Hospital, Mumbai,

Maharashtra, India

\section{Akash Shakya}

Senior Resident, Department of

Orthopaedics, TNMC \& BYL

Nair Hospital, Mumbai,

Maharashtra, India
Corresponding Author: Ghanshyam Kakadiya Senior Resident, Department of Orthopaedics, TNMC \& BYL

Nair Hospital, Mumbai,

Maharashtra, India

\section{Study of the role of surgical drain on outcome of total knee replacement surgery}

\author{
Ghanshyam Kakadiya, Yogesh Soni, Viraj Gandbhir and Akash Shakya
}

DOI: https://doi.org/10.22271/ortho.2019.v5.i3n.1634

\section{Abstract}

Background: Study the effect of drain on outcome of primary TKR.

Method: Prospective study, 150 patients with primary TKR randomly divided into three groups, without drain: Group-A, Group-B: drain for 24 hours and Group-C: drain for 48 hours. With minimum follow-up period of 1 year. Functional outcome majored with KSS-Knee Society Score and VAS-Pain Visual Analogue Scale.

Result: The decrease in haemoglobin in post-operative $3^{\text {rd }}$ day was statistically significant between all the groups ( $\mathrm{p}<0.05$ ). The mean drop in haemoglobin is group-B was $1.84 \mathrm{gm} \%$ and $2.59 \mathrm{gm} \%$ in Group-C. Patients in group with no drain are having maximum post-operative pain scores among the all groups. The post-operative Knee Society Score in all postoperative follow up at 1 month, 3 months \& 1 year, with the scores being lower in patients in whom drain was not kept. There is no significant difference in KSS \& between two groups with drain at 1 and 3 months follow up, but there is significant difference in Knee Society Score in between these two groups at 1 year follow up $(\mathrm{p}=0.004)$. There are 7 patients in group-A who are having superficial infection post-operatively in comparison to 2 patients in group-A \& 3 patients in Group-C.

Conclusion: Post operatively significantly higher blood loss is associated with use of drain, not using a drain is associated with significantly higher pain in immediate postoperative period and Use of drain for 48 hours postoperatively is associated with significantly better outcome of total knee replacement after 1 year.

Keywords: Total knee replacement, surgical drain, osteoarthritis, blood loss, KSS

\section{Introduction}

Arthritis of the knees in the advanced stages is a painful and debilitating disorder that results in significant deterioration in the quality of life. TKR-Total Knee Replacement has long been accepted as the final line of management in such patients ${ }^{[1]}$. The first true femoral and tibial articular replacement (Metal-on-metal) was performed in the 1950's ${ }^{[2]}$. Over the past few decades there have been tremendous advances in the surgery making TKR the most commonly performed and successful surgeries in terms of clinical and functional outcome ${ }^{[2]}$. It has been proven to be a successful treatment for knee arthritis with an expectable revision rate less than $5 \%$ within 10-years, a long-lasting functional improvement of more than $30 \%$ in any assessment score ${ }^{[3]}$. Despite this success, there still remain some technical issues to which a clear answer is yet not available. Moreover, much of the indexed publication and literature available on TKR is based on studies conducted outside the Indian subcontinent and it is already well know the requirements and expectations of Asian people is different in comparison to patients in the western world [4]. In 2011 alone 70,000 total knee arthroplasty surgeries were performed across India as per the Frost and Sullivan research, which also predicts a growth in numbers by $26.7 \%$ from 2010 to $2018^{[5]}$. Drains have been used in surgery since Hippocrates first recommended use of tubes for surgical drainage ${ }^{[6]}$. Most surgeons today have developed their own personal opinion regarding placement of drains following surgery, which is reflected by variability in whether or not drains are put, the number of drains put, whether they are placed in superficial or deep tissues, and time of removal of drains post operatively ${ }^{[7]}$. The advantages of using drains in TKR that they help by draining hematomas. 
That would otherwise create pressure, delay healing and possibly predispose to infection, however at the same time they pose a risk of retrograde infection and delay restoration of mobility ${ }^{[8]}$. Study purpose is to determine the effect of the mentioned variables, placement of a drain, individually on the functional outcome of TKR.

\section{Materials and Methods}

Prospective study from May 2016 to MAY 2019, 50 patients in each group. Average patient's age in different groups is almost similar and statistically not significant ( $\mathrm{p}$ value 0.913 ). There are 21 males \& 29 females in group with no drain, 19 males \& 31 females in both the groups with drain. Left: Right ratio are 24:26, 25:25 \& 26:24 respectively in group-A, B \& C. All patients were screened using the inclusion criteria: Primary Osteoarthritis \& Rheumatoid arthritis and exclusion criteria: Revision arthroplasty cases \& Secondary Osteoarthritis and previously operated cases for fracture/deformity around the knee joint. These patients were divided randomly into three groups. Group-A: no placement of drain, Group-B: Drain removal on post-operative day-1 \& Group-C: Drain removal on post-operative day-2. The detailed history was taken. Radiological Assessment done in form of 1. Full-length extremity scanogram to know the mechanical and anatomical axis, 2.Load bearing-standing AP view, 3. Lateral view in 30 degrees of flexion of the affected limb, 4. Skyline view. Radiologically following points were noted for patients in whom the effect of patellar resurfacing was being studied- Kellegren Lawrence grading, InsallSalvati ratio and Blumensaat line.

\section{Surgical procedure}

All surgeries performed by a single senior doctor as a primary surgeon using PFC Sigma PS, DePuy implants. Tourniquet was used in all patients and blood loss was recorded. The operation time was recorded. Wound closure was done in layers after inserting a surgical drain tube inside the joint (Groups B and C). No drainage implanted in group A. The standard dressing with compression bandage was applied. Low molecular weight heparin was given to all the patients 12 hours prior the surgery.

\section{Post-operative protocol}

3rd generation Cephalosporin twice a day with $750 \mathrm{mg}$
Amikacin IV once a day was administered for 5 days followed by oral antibiotics till suture removal. Drain removal was done after 24 and 48 hours according to study group. Postoperative on day- $12^{\text {th }}$ suture removal was done.

\section{Post-operative physiotherapy}

On $2^{\text {nd }}$ post-operative day Static Quadriceps, straight leg rising and Gentle knee flexion exercises were started. Weight bearing walking was started from $2^{\text {nd }}$ day. As soon as pain subsided hamstrings exercises were started. Stair climbing was encouraged from $5^{\text {th }}$ post-operative day.

\section{Data collection}

Pre-operative and post-operative patients data collected to compare Pain VAS, Haemoglobin \& KSS at 1, 3 \& 12 months follow up and amount of blood collected in drain post operatively and incidence of infections post operatively.

\section{Statistical analysis}

The paired t-test was used for comparison of the variables within each group \& the unpaired t-test used for comparison among means for continuous variables in between two groups. For the level of statistical significance $p$ value $<0.05$ was taken, i.e. whatever (Mean/distribution) difference observed was real and can be attributed to the intervention in this study.

\section{Result}

The mean pre-operative pain visual analogue score was 8.88 in group with no drain, 9.16 in group-drain for 1 day \& 8.56 in group-for 2 days. There was no statistically significant difference between the all group in relation to pre-operative knee flexion $(\mathrm{p}=0.761)$, fixed flexion deformity $(\mathrm{p}=0.084)$. The pre-operative knee society was statistically significantly low in 48 hours drain groups $(\mathrm{p}=0.00)$.

Table 1: Demographic data

\begin{tabular}{|c|c|c|c|}
\hline & Group-A & Group-B & Group-C \\
\hline Data size & 50 & 50 & 50 \\
\hline M:F & $21: 29$ & $19: 31$ & $19: 31$ \\
\hline BMI & $28.9 \pm 1.2$ & $29.5 \pm 1.52$ & $29.1 \pm 1.2$ \\
\hline OA & 41 & 41 & 40 \\
\hline RA & 9 & 9 & 10 \\
\hline
\end{tabular}

Table 2: Comparison of detection indexes

\begin{tabular}{|c|c|c|c|}
\hline Group & A & B & C \\
\hline Operation time (minute) & $66.17 \pm 10.62$ & $66.83 \pm 12.50$ & $71.67 \pm 11.44$ \\
\hline Blood loss(ml) & $243 \pm 51.30$ & $270.50 \pm 66.11$ & $252 \pm 25.13$ \\
\hline Drainage volume (mL) & - & 463 & 542.3 \\
\hline Hb drop (gm/dl) & 1.6 & 1.84 & 2.59 \\
\hline VAS 1 month & 1 & $1.3 \pm 0.47$ & $0.83 \pm 0.37$ \\
\hline 3 month & $0.5 \pm 0.1$ & 0.2 & 0 \\
\hline 1 year & $0.17 \pm 0.03$ & 0 & 0 \\
\hline Superficial infection & 7 & 2 & 0 \\
\hline Deep Infection & 1 & 0 & $42.7 \pm 4.2$ \\
\hline KSS Pre-op & $42 \pm 3.5$ & $41.7 \pm 4.5$ & $72.0 \pm 3.5$ \\
\hline Post-op 1 Month & $57.3 \pm 2.5$ & $70.4 \pm 2.2$ & $83.0 \pm 5.2$ \\
\hline 3 Month & $74.6 \pm 1.5$ & $82.5 \pm 5.0$ & $85.0 \pm 5.2$ \\
\hline 1 year & $77.6 \pm 2.4$ & $83.5 \pm 5.0$ & \\
\hline
\end{tabular}

\section{Blood loss- post-operative}

The mean total blood loss in two groups with drain for 24 and 48 hours are $463 \mathrm{ml}$ and $542.3 \mathrm{ml}$ respectively. $82.34 \%$ of the total blood loss in group-C in first 24 hours. There is no significant statistically difference in blood loss in $1^{\text {st }} 24$ hours in group-B \& $\mathrm{C}$. 


\section{Post-operative haemoglobin drop}

Post-operatively the decrease in haemoglobin in postoperative $3^{\text {rd }}$ day was statistically significant in between three groups $(\mathrm{p}<0.05)$ and; in between groups with 24 hours and 48 hours drain $(\mathrm{p}<0.05)$. The mean drops in haemoglobin from pre-operative to day 3 post-operatively is $1.84 \mathrm{gm} \%$ in 24 hours group and $2.59 \mathrm{gm} \%$ in 48 -hour group. 7 patients in group with 48-hour drain required post-operative blood transfusion in comparison to 4 patients each in no drain and 24 hours drain group.

\section{Post-operative pain (VAS)}

Post operatively there was significant difference $(\mathrm{p}=0.000)$ between the all 3 groups in the VAS scores on 1, 3 and 12 months follow up. Patients in group-with no drain were having maximum pain scores in between three groups. Postoperative the KSS Knee score which was revised in 2011 was used for patient evaluation. Postoperative there was statistically significant difference in knee society score $(p=0.00)$ between the group of patients without drain as compared to those with drain in all postoperative follow-up (1,3 \& 12 months), The scores being lower in patients in whom drain was not kept. There was no significant difference in $\mathrm{KSS}$ in between two groups with drain at $1 \& 3$ months follow-up, but there was significant difference in Knee score between these two groups at the 12 months follow up $(\mathrm{p}=0.004)$.

\section{Postoperative complication}

There were 7 patients in no drain group who were having superficial infection post-operatively in comparison to 2 patients in 24 hours drain group \& 3 patients in 48 hours drain group. Occurrence of superficial infection in between three group is statistically significant for patients in no drain group. The number of soakage dressing change was also significantly more in patients with no drain group $(p=0.00)$. There was one incidence of deep infection which was detected 3 months after surgery in patient without a post-operative drain. Open debridement, antibiotics beads with change of poly insertion was done.

\section{Discussion}

Surgical suction drain is viewed as an important tool in postoperative management in number of orthopaedic surgery [9]. The duration for which a suction drain should be kept has

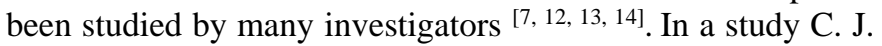
Drinkwater \& Michael J. Nell ${ }^{[12]}$ advocate the use of drain to prevent infection and perioperative wound morbidity by reducing hematoma formation while also demonstrating that the drains themselves are a significant infection risk. A number of prospective studies of surgical drain in total joint replacement demonstrate no statistical differences in infection rate; wound healing and post-operative rehabilitation in patients with-without drain [7, 10, 11, 15]. Majority of these studies indicate that the group with suction drain had a greater fall in haemoglobin post-operatively, required more blood transfusions and had drain specific complications. In our study we found that the post-operative blood loss is significantly more in patients with drains. Haemoglobin level drop from its pre-operative value is significant in case of patients with drain for 48 hours and the requirement of transfusion of blood post-operatively is also significantly higher in this group. In 48-hour drain group the maximum amount of blood $(82.03 \%)$ which has drained through suction drain is in first 24 hours. This was in concordance with the study by K M Willet ${ }^{[16]}$ which had shown that the majority of wound aspiration has occurred and the risk of haematoma formation is not reduced by the continued presence of the drain by 24 hours postoperatively. In our study we therefore found it more advantageous to use drain post-operatively for 24 hours. Patients with no drain post-operatively were found to have more soakage in early post-operative days in comparison to others and the incidence of minor wound complication was also significantly more. In our study there was one patient in the group without drain, who had deep wound infection. We also find that the knee society is insignificantly more in patients with drain postoperatively in comparison to patients without any drain. It has been theorised that omitting drains would lead to haematoma formation that then might lead excessive pain in immediate post-operative period and later on intra-articular fibrosis ${ }^{[10]}$. Results of our study partly support this particular theory as pain was more in the initial period however knee range of motion difference was not significant.

\section{Conclusion}

Use of surgical drain in TKR is associated with significantly higher blood loss post operatively. Not placing a drain after TKR was associated with significantly higher pain in the early post-operative period. Post operatively 48 hours use of drain is associated with significantly better outcome of total knee replacement after 1 year.

\section{References}

1. Buckwalter JA, Lohmander S. Operative treatment of osteoarthrosis. Current practice and future development; J Bone Joint Surg Am. Sep. 1994; 76(9):1405-18.

2. Ranawat CS. History of total knee replacement; J South Orthop Assoc. Winter. 2002; 11(4):218-26.

3. Liitzner J, Hubel U, Kirschner S, Gunther KP, Krummenauer F Chirurg. Long-term results in total knee arthroplasty. A meta-analysis of revision rates and functional outcome. 2011; 82(7):618-24.

4. Yoo JH, Chang CB, Kang YG, Kim SJ, Seong SC, Kim TK. Patient expectations of total knee replacement and their association with sociodemographic factors and functional status; J Bone Joint Surg Br. 2011; 93(3):33744. Doi: 10.1302/0301-620X.93B3.25168.

5. Busch CA, Shore BJ, Bhandari R, Ganapathy S, MacDonald SJ, Bourne RB et al. Efficacy of periarticular multimodal drug injection in total knee arthroplasty. A randomized trial. J Bone Joint Surg Am. 2006; 88:95963.

6. Kim YH, Cho SH, Kim RS. Drainage versus nondrainage in simultaneous bilateral total knee arthroplasties; Clin Orthop Relat Res. 1998; 347:188-9.

7. Luca Amendola, Domenico Tigani, Matteo Fosco, Dante Dallari. History of Condylar Total Knee Arthroplasty, 2017. ISBN: 978-953-307-841-0.

8. Ranawat AS, Ranawat CS. The history of total knee arthroplasty; The Knee Joint, 2012, 699-707.

9. Moss JP. Historical and current prospective on surgical drainage; Surgery, Gynecology, and Obstetrics. 1981; 152:517-527.

10. Reilly TJ, Gradisar IA Jr, Pakan W, Reilly M. The use of postoperative suction drainage in total knee arthroplasty. Clin Orthop Relat Res. 1986, 208.

11. Beer KJ, Lombardi AV, Mallory TH, Vaughn BK. The efficacy of suction drains after routine total joint arthroplasty; The Journal of Bone and Joint Surgery Am. 
1991; 73(4):584-587.

12. Drinkwater CJ, Neil MJ. Optimal timing of wound drain removal following total joint arthroplasty; J Arthroplasty, 1995.

13. Holt BT, Parks NL, Engh GA, Lawrence JM. Comparison of closed-suction drainage and no drainage after primary total knee arthroplasty. Orthopedics. 1997; 20:1121-5.

14. Zamora Navas P, Collado Torres F, De la Torre-Solis F. Closed suction drainage after knee arthroplasty. A prospective study of the effectiveness of the operation and of bacterial contamination' Acta Orthop Belg.

15. Jenny JY, Boeri C, Lafare S. Drainage does not increase complication risk after total knee prosthesis implantation: a prospective, comparative, randomized study; Knee Surg Sports Traumatol Arthrosc, 2001.

16. Willett KM, Simmons CD, Bentley G. The effect of suction drains after total hip replacement. J Bone \& Joint Surgery (Br). 1988; 70-B:607-10. 